\title{
A Pesquisa como Eixo Interdisciplinar no Estágio e a Formação do Professor Pes- quisador-Reflexivo
}

\author{
The Research As Interdisciplinar Basis \\ In Training And The Background of The \\ Reflexive Researcher Teacher
}

\author{
Evandro GHEDIN*
}

\begin{abstract}
RESUMO
A experiência de estágio na formação de professores representa uma primeira aproximação do professor com seu campo de atuação profissional. Tal experiência o obriga a realizar um trabalho de síntese entre teoria e prática educativa. Acreditase que tanto o desenvolvimento profissional quanto o curricular só poderão dar-se no contexto de um processo que articule intimamente teoria e prática educativa. Em nosso entendimento, o eixo que articula esses dois espaços da formação é o conceito de pesquisa, enquanto instrumento epistemológico e metodológico do processo de construção do conhecimento do professor em formação. Compreendemos que o processo formativo fundado sobre a reflexão na ação e sobre a ação, ao mesmo tempo em que valoriza a prática docente como fonte de pesquisa e de autonomia do professor, lhe dá a responsabilidade por seu desenvolvimento profissional. O presente trabalho de pesquisa, em sintonia com o debate sobre a articulação teoria e prática, levanta a discussão sobre a importância da pesquisa na formação de professores, enfatizando-a como princípio formativo e científico. Trata-se de uma concepção de formação do professor que afirma que o mesmo deve ser capaz de produzir conhecimento a partir de sua prática educativa, superando, dessa forma, as tradicionais perspectivas acadêmica e técnica de formação de professores. Dentro dessa perspectiva destacam-se algumas propostas que estimulam uma revisão na formação acadêmica dos professores: o professor investigador em aula e o professor pesquisador. No âmbito da formação especificamente acadêmica a perspectiva do professor/pesquisador traz algumas implicações que obrigam a uma revisão do
\end{abstract}

* Mestre em Educação pela Fundação Universidade do Amazonas - UFAM. Pesquisador do Programa de Estudos Pós-Graduados em Educação da Universidade de São Paulo - USP. Professor da Universidade do Estado do Amazonas - Manaus, UEA e da Faculdade de Educação da Universidade de São Paulo - FEUSP. E-mail: ghedin@usp.br

Olhar de professor, Ponta Grossa, 7(2): 57-76, 2004. 
processo formativo e da concepção curricular. Uma dessas implicações diz respeito às formas de superação do tradicional distanciamento entre pesquisa acadêmica e prática pedagógica. Nessa direção, compreendemos que a prática reflexiva tem o mesmo sentido e direção da prática orientada pela pesquisa. Daí a necessidade de implementar no curso de formação de professores a pesquisa como alternativa de crescimento profissional para professores em formação.

Palavras-chave: estágio - pesquisa em estágio - interdisciplinaridade - professorreflexivo - professor-pesquisador.

\begin{abstract}
The experience of training into teaches background represents a first nearness of their professional acting field. Such experience takes them to accomplish a synthesis work between theory and educative practice. It' believable that such the professional as the curricular development, can happen into a context of process that closely articulates theory and educative practice. We understand the axis that articulates these two spaces of background is the research concept, as epistemological and methodological instrument in the knowledge elaborating process of teacher in formation. We consider that formative process with the basis on reflection on the action and over the action, at the same time that values the teaching practice as source of research and the teacher's autonomy, attributes him responsibility for his professional development. This work of research, linked to debate about the articulation theory and practice, points to the discussion concerning to research on teachers' background, underlining it as formative and scientific beginning. It brings a conception of teacher's formation that is supposed him must be able to elaborate knowledge by his educative practice, overcoming, this way, the traditional academic and technical perspective of teachers' background. Within this perspective, some proposals are stood out in the way to stimulate a review into academic teachers' formation: the investigator teacher in classroom and the researcher. In the ambit of specific academicals formation the perspective of teacher/researcher brings some implications that ask formative process and curricular conception review. One of them is about the way of overcoming of the traditional distantly between academic research and pedagogical practice. On this direction we understand that the reflexive practice has the same sense and direction of oriented practice. That's why the necessity of implementation into teachers' course the research as alternative of professional growing to teachers in formation.
\end{abstract}

Key words: training - research in training - interdisciplinarity - reflexive teacher researcher teacher. 


\section{POR QUE A PESQUISA COMO EIXO INTERDISCIPLINARENTRE O ESTÁGIO E A FORMAÇÃO DO PROFESSOR PESQUISADOR-RE- FLEXIVO?}

O conhecimento produzido em educação não tem a mesma perspectiva do conhecimento que se produz na ciência, pois enquanto a ciência pensa matematicamente, em educação procura-se pensar o mundo real e imediato que, muitas vezes, condiciona o que somos ou potencializa o que podemos ser enquanto humanidade. Isso quer dizer que a educação, além de ser científica, é um processo que se desenvolve estrapolando o campo científico, pois preocupa-se fundamentalmente com as formas de ação que institui no campo político, ético, cultural e social.

Portando, produzir conhecimento nas Ciências da Natureza e na Educação exige métodos e metodologias totalmente diferenciadas. Em educação o sujeito encontra-se mergulhado na realidade, de modo que a tradicional separação entre sujeito e objeto, posta por Aristóteles e tantos outros, confunde-se no ato da pesquisa. Isso acontece porque em educação o próprio sujeito que investiga pode ser objeto de pesquisa. Neste caso, organiza-se um conjunto de perspectivas que procuram oferecer alternativas $^{1}$ a essa modalidade de produção do conhecimento.

O modelo tradicional de ensino de Estágio tem se caracterizado fundamentalmente por uma cultura de cunho tecnicista, seguindo um modelo técnico e científico (com base nas ciências naturais), fundado quase que exclusivamente ao nível da informação e tendo como habilidade cognitiva básica a memória, a descrição dos dados e o relato da experiência como base do conhecimento. Pensamos que esse procedimento como base para a formação de futuros professores não é suficiente, embora possa ser necessário para seu trajeto inicial. Tal modelo de aprendizagem não dá conta da complexidade do conhecimento que o professor precisa dominar para responder às necessidades da sociedade do presente. $\mathrm{O}$ que queremos dizer é que somente o dado e a informação não são suficientes para que possamos produzir conhecimento na universidade, especialmente aquele constituidor do modo como os alunos (futuros professores) serão formados.

O conhecimento que se busca na

\footnotetext{
${ }^{1}$ A pesquisa em educação, nas duas últimas décadas, tem revelado uma ampla e fértil discussão no campo epistemológico e metodológico de seu desenvolvimento no Brasil. Como exemplo podemos destacar, entre outros: Alves (2002), André (2002), Demo (2002), Franco (2000), Franco (2002), Gatti (1997). Em relação a Pesquisa-ação, podemos destacar Barbier (2002), em História de Vida; na Pesquisa Colaborativa merece destaque o trabalho de Pimenta (1999); na Pesquisa Participante são indispensáveis as reflexões de $\mathrm{Br}$ andão (1999; 2003), Freire (1999) e Borda (1999).
}

Olhar de professor, Ponta Grossa, 7(2): 57-76, 2004. 
universidade - o que não é o caso de todas - é aquele que se produz e não a sua mera reprodução. Uma universidade que não se arvora na produção da pesquisa e na elaboração de novos conhecimentos cumpre uma função acadêmica, mas não desempenha seu papel político em fazer avançar o saber da sociedade. Sabemos que o conhecimento não consiste num conjunto de informações que vamos acumulando, mas num processo de significação e de sentido que vamos construindo coletivamente. Nessa perspectiva, a formação consiste num processo de preparação intelectual que pretende responder às necessidades da realidade em que nos encontramos, enquanto sujeitos históricos.

É claro que esse modelo responde a uma tradição na educação brasileira, pois a universidade brasileira foi - e em certos aspectos ainda é marcada pelo Tomismo de tradição jesuítica e pela tradição positivista que, de certo modo, negligencia a formação epistemológica (filosófica, teórico-prática) em detrimento de uma formação técnica (exclusivamente centrada na prática e no saber fazer ${ }^{2}$ ). Faz sentido aqui lembrar que quando a educação escolar era destinada às elites, propunha-se uma formação cultural; quando ela se destina às massas, é um ensino de caráter técnico voltado para a formação do trabalhador, negando-lhe o acesso à cultura produzida e organizada pelo ser humano ao longo de sua história.

Insistimos que o conhecimento produzido na universidade exige uma postura investigativa; portanto, uma outra pedagogia. Assim, o conhecimento há de ser produzido de forma competente, crítica e criativamente. Vale ressaltar que o curso de formação de professores, apesar de ser uma exigência histórica da sociedade brasileira, é algo que tem adquirido importância no país na última década do século XX. Por isso, faz-se necessário desenvolver um modelo de produção de conhecimento, no processo de formação de professores, que se oriente por padrões científicos, de modo que se possa, sistemática e metodicamente, criar um mapeamento das práticas que orientam as ações dos professores no exercício de sua profissionalidade.

Ao formar professores(as) para atuar nas escolas ao nível do Ensino Infantil e Fundamental, é preciso ter como foco de aprendizagem e pesquisa esse mesmo nível de ação e prática social. A universidade, além do cuidado com a formação voltada para o ensino, não pode descuidar-se de uma preocupação com a formação do

\footnotetext{
${ }^{2}$ Com isso não queremos dizer que o aluno (futuro professor) não precisa aprender a fazer, mas queremos enfatizar que para aprender a fazer ele necessita, antes, aprender a pensar melhor a realidade. Isso só é possível se ele for munido com um conjunto de instrumentos que ampliem a possibilidade que tem de compreender e interpretar a realidade de modo significativo e que responda aos nossos desafios.
}

60 Olhar de professor, Ponta Grossa, 7(2): 57-76, 2004. 
cientista da educação - aquele estudioso que se volta para os problemas que atingem a educação na sua interface social. Isso pode dar-se mais na pós-graduação, mas nada impede que se inicie na graduação. É preciso, pois, pensar um conjunto de articulações no interior do curso de graduação, aliando-se um conjunto de disciplinas que permitam pensar sistematicamente um dado objeto a ser investigado ao longo do processo formativo. Assumir o estágio como prática orientada pela pesquisa pode ser uma maneira para criar condições para o surgimento de atitudes mais interdisciplinares.

Estamos buscando um "modelo" em que a construção da identidade profissional do futuro professor seja pensada e elaborada não somente em relação à pratica, mas envolvida num conjunto de ações que lhe permitirão ampliar o horizonte de sua compreensão e de sua atuação no campo de trabalho, orientando-se pela construção do conhecimento a partir de um processo sistemático e metódico de pesquisa. Nesse sentido, é significativa a pesquisa desenvolvida por $\mathrm{Pi}$ menta (2000), que procura verificar os processos de construção identitária dos futuros professores, oriundos das licenciaturas, através da elaboração dos saberes da docência que são produzidos no espaço pedagógico, na área de conhecimento e pela experiência. A autora questiona a possibilidade de a construção do saber docente acontecer a partir da prática pedagógica dos professores. A categoria principal que norteia a pesquisa é a atividade prática que os professores realizam em escolas públicas, como forma de desenvolvimento profissional e, nessa atividade, o modo como se dá o processo de construção de seu saber-fazer docente.

Pensa-se num profissional que seja capaz de atuar competentemente como docente e produzir conhecimento sistemático a partir dessa sua prática. Compreendemos que o professor é competente à medida que pesquisa. Ele alia a docência à pesquisa como forma de articular a teoria-prática, assim como de expressar sua competência técnica e seu compromisso político com a práxis de professorar.

Colocando a atividade docente como objeto de investigação, necessário se fez compreendê-la em suas vinculações com a prática social na sua historicidade. Apreender na cotidianeidade a atividade docente dos alunos supõe não perder de vista a totalidade social, pois sendo a escola parte constitutiva da práxis social, representa no seu dia-a-dia as contradições da sociedade na qual se localiza. Assim, o estágio como estudo, pesquisa e prática pedagógica da atividade docente cotidiana envolve o exame das determinações sociais mais amplas, bem como da organização do trabalho nas escolas.

Compreendendo o ensino como atividade específica, mas não exclusiva, do professor, entendemos o estágio, enquanto teoria-prática do ensi- 
no-aprendizagem, como uma área de conhecimento fundamental no processo de formação de professores. Assim, no desenvolvimento da disciplina de Didática vincula-se com o estágio profissional, na medida em que colocamos o ensino como atividade específica do professor e como tema de estudos aos alunos do curso de formação de professores. Coloca-se em questão o papel do conhecimento na sociedade contemporânea. O que é o conhecimento? O que é conhecer e produzir conhecimento? Qual o papel da escola frente ao conhecimento? Como a escola trabalha o conhecimento? Essas questões se colocam a partir das transformações tecnológicas que vêm ocorrendo nos últimos anos e do mundo do trabalho que se apresenta nesse contexto. Os alunos do Curso de Formação de professores, enquanto especialistas numa área do conhecimento, estão se indagando sobre o seu trabalho com o conhecimento na sociedade e, especialmente, na escola (na sua atividade de ensinar). Por isso, no desenvolvimento da pesquisa é necessário introduzir uma nova categoria de análise, que é o trabalho do professor com o conhecimento na escola (MACHADO, 1995; MORIN, 1994).

As três grandes categorias da pesquisa, que emergem dos estudos teóricos no campo da formação de professores, podem assim ser sintetizadas: como se dá o processo de construção do saber fazer docente (ensinar) na atividade prática de professo- res concretamente situados em escolas (públicas e privadas na cidade de Manaus)? Como a organização do trabalho na escola (ou o entorno administrativo, burocrático da sala de aula) determina essa construção? Como os professores se colocam diante do conhecimento na sociedade contemporânea (e como lidam com ele na atividade de ensinar nas escolas)? Tais categorias desdobraram-se em outras duas: saberes da docência e identidade do professor - saberes da experiência, das áreas de conhecimento e pedagógicos; e relações entre pedagogia, ciências da educação e didática. Estas, por sua vez, indicaram a importância de conceitos como professor/pesquisador; reflexão/pesquisa da ação; metodologia investigação/ação/intervenção; a reflexão na ação/sobre a ação como metodologia de formação de professores.

Do ponto de vista metodológico, uma questão fundamental emerge como central para o desenvolvimento da pesquisa: seria esta uma pesquisa-ação?

Considerar a prática na sua concretude como caminho para re-significar as teorias (e as práticas) pedagógicas, no sentido de novas formulações teórico-práticas, requer, necessariamente, a utilização das abordagens qualitativas, especialmente a pesquisa-ação-colaborativa. Para compreender o fenômeno - prática docente - em suas múltiplas determinações, precisamos realizar investigação teórica sobre teoria didática, for- 
mação de professores e ensino de didática, e o modo de conduzir o estágio profissional.

Diante da proposta em que se assume o ensino através da pesquisa como possibilidade de desenvolvimento do estágio profissional, requer assumir-se uma postura teóricometodológica que responda ao desafio de formar o novo professor através da pesquisa como prática profissional. Nessa perspectiva podemos assumir que, por se tratar de uma pesquisa qualitativa, com um trabalho de reflexão sobre a prática, procurar-seá promover a aproximação dos professores com a pesquisa, tornandoos também participantes, através do entendimento da pesquisa e seus objetivos, ao mesmo tempo em que os alunos compartilham textos com os professores, para participar dos rumos da pesquisa e das atividades desenvolvidas no estágio profissional. A presente proposta procura dar estímulo à iniciativa e projetos dos professores e dos estudantes, que procurarão relatar com maior consciência sua prática a partir do trabalho com a pesquisa, sistematizando mais suas aulas, o que será considerado o embrião de um resultado de maior reflexão sobre a prática docente.

2.FUNDAMENTOS EPISTEMOLÓGICOS PARA O ESTÁGIO PROFISSIONAL CENTRADO NA PRÁTICA DA PESQUISA, COMO PROPOSTA PARAAFORMAÇÃO DO PROFESSOR REFLEXIVO-

\section{PESQUISADOR}

As pesquisas de Pimenta (1999; 2002a; 2002b), Abdalla (2000) e Guimarães (2001), realizadas com professores nas escolas, orientam e dão base para que possamos propor e desenvolver o estágio profissional numa perspectiva de pesquisa, como orientador da prática profissional do futuro professor. Dessas pesquisas consolidam-se algumas questões que justificam uma proposta teórica na área de formação de professores. As pesquisas realizadas por Mizukami e Rodrigues (2002), Marin (1998), Brezinski (1996), Libâneo (1998), Contreras (1997), Sacristán (2002; 1999), Sacristán e Gomez (1992), Zeichener e Liston (1990), Perrenoud (1992), Heargreaves (1996), Elliot (1998), Gauthier (1998), Baird, Mitchell e Northfield (1987), Carr e Kemmis (1996), Porlán (1987), Charlot (1995), Alarcão (1996), Zaragoza (1999) evidenciam movimentos que orientam a possibilidade da organização do estágio centrado num processo de pesquisa que intervém na realidade educativa.

Podemos dizer que a profissão docente é uma prática educativa que, como tantas outras, constitui uma forma de intervenção na realidade social. Entendemos que a atividade docente é uma das atividades de ensino e formação ligadas à prática educativa mais ampla que ocorre na sociedade. Na sua acepção corrente, é definida como uma atividade prática. O pro- 
fessor em formação está se preparando para efetivar as tarefas práticas de ser professor, dado que não se trata de formá-lo como reprodutor de modelos práticos dominantes, mas como um profissional capaz de desenvolver a atividade material para transformar o mundo natural e social humano. Transformando a prática docente num processo de pesquisa, é possível apreender na cotidianeidade. A atividade docente supõe não perder de vista a totalidade social, pois sendo a escola parte constitutiva da práxis social, representa no seu dia-a-dia as contradições da sociedade na qual se localiza. Assim, a prática do professor como atividade docente cotidiana envolve a compreensão dos determinantes sociais mais amplos, bem como o conhecimento da organização do trabalho nas escola. Esse conhecimento é fundamental para o futuro professor no processo da aprendizagem inicial na qual se desenvolve o estágio.

Os estudos de Pimenta (2002c) permitem estabelecer a importância da relação entre pesquisa e formação de docentes, realçando que a pesquisa deve se realizar a partir da formação e prática dos docentes; e esta deve organizar-se a partir dos dados e informações advindas da pesquisa e referendadas como teoria.

Segundo Pimenta (2000), é importante ressaltar que o saber docente não é formado apenas da prática; é também nutrido pelas teorias da educação. Porém, o acesso à teorização da prática só é possível por um processo de reorganização interpretativa do fazer, à luz de outras interpretações a respeito da realidade. Desse modo, podemos dizer que a teoria tem importância fundamental na formação dos docentes, pois dota os sujeitos de variados pontos de vista para uma ação contextualizada, oferecendo perspectivas de análise para que os professores compreendam os contextos históricos, sociais, culturais, organizacionais e de si próprios como profissionais.

A partir do pensamento de Habermas (1982) é possível compreender que a reflexão não é apenas um processo psicológico individual, uma vez que implica a imersão do homem no mundo da sua existência, um mundo carregado de valores, intercâmbios simbólicos, correspondências afetivas, interesses sociais e cenários políticos. Nesse sentido, torna-se necessário estabelecer os limites políticos, institucionais e teóricometodológicos relacionados à prática reflexiva, para que não se incorra numa individualização do professor, advinda da desconsideração do contexto em que ele está inserido.

A transformação da prática dos professores deve se dar, pois, numa perspectiva critica. Assim, deve ser adotada uma postura cautelosa na abordagem da prática reflexiva, evitando que a ênfase no professor não venha a operar, estranhamente, a separação de sua prática do contexto organizacional no qual ocorre. Fica, 
portanto, evidenciada a necessidade da realização de uma articulação, no âmbito das investigações sobre prática docente reflexiva, entre práticas cotidianas e contextos mais amplos, considerando o ensino como prática social concreta. Essa articulação, em nosso entender, só pode dar-se por um processo de investigação. Por isso é fundamental que os professores, já no seu processo de formação inicial, possam fazer uma experiência de pesquisa. Pensamos que o estágio configura-se como um tempo e um espaço privilegiado para esse processo formativo.

Essa dinâmica torna-se possível quando o estágio constitui-se em oportunidade coletiva para elaboração do conhecimento sobre a prática, além de ser espaço de reelaboração de saberes que se processam na prática de ensino. Para Stenhouse (1991, p. 12), o professor, como pesquisador de sua própria prática, transforma-a em objeto de indagação dirigida à melhoria de suas qualidades educativas. A pesquisa na docência constitui um diálogo e fusão de idéias educativas e de ações pedagógicas que se justificam mutuamente. A idéia do professor como pesquisador está ligada, portanto, à necessidade dos professores de pesquisar e experimentar sobre sua prática enquanto expressão de determinados ideais educativos.

Tal processo de formação pode favorecer a compreensão dos alunos ou estimular seu pensamento crítico.
Essas são pretensões educativas que se abrem ao inesperado porque se referem a dimensões criativas das pessoas. Definem um potencial para desenvolver nos alunos que pode abrirse a possibilidades imprevistas, tanto porque se refere à experiência educativa a que pode dar lugar, como pelas aprendizagens que podem realizar-se.

Assim, a atitude investigadora que propõe Stenhouse (1991) consiste em uma disposição para examinar a própria atividade prática, com sentido crítico e de forma sistemática. Desse modo, o professor, como investigador de sua própria prática, converte-a em objeto de indagação dirigida a maioria de suas qualidades educativas. A investigação na prática docente constitui num diálogo e fusão de idéias educativas e de ações pedagógicas que se justificam mutuamente. A idéia do professor como investigador está ligada, portanto, à necessidade que têm os professores de investigar e experimentar sobre sua prática docente, enquanto que esta aspira a ser a expressão de determinados ideais educativos.

Segundo Elliott (1990), tanto o pensamento como a prática de Stenhouse estavam condicionados pela idéia de fazer experiência com o currículo. Para Stenhouse, a pesquisa surge a partir da necessidade de colocar à prova as idéias expressas em uma proposta curricular.

Embora Stenhouse tenha iniciado essa reflexão sobre o professor pes- 
quisador, sua abordagem não inclui a critica ao contexto social em que se dá a ação educativa. Assim, reduz a investigação sobre a prática aos problemas pedagógicos que geram ações particulares em aula. Para Carr e Kemmis (1996), por exemplo, a centralidade na aula como lugar de experimentação e de investigação e no professor como o que se dedica, individualmente, à reflexão e à melhoria dos problemas, é uma perspectiva restrita, pois desconsidera a influência da realidade social sobre ações e pensamentos e sobre o conhecimento como produto de contextos sociais e históricos. Nesse sentido, há que se aceitar a afirmação de Giroux (1997), de que a mera reflexão sobre o trabalho docente de sala de aula é insuficiente para uma compreensão teórica dos elementos que condicionam a prática profissional. Também Lawn (1993) analisa que uma coisa é identificar o lugar onde o professor realiza sua função; outra é reduzir o problema a esse lugar. Por isso, o processo de emancipação a que se refere Stenhouse é mais o de liberação de amarras psicológicas individuais, do que o de uma emancipação social.

Segundo Contreras (2002, p. 121), foi Elliott (1989; 1990) quem melhor expressou o que significa a idéia do professor como pesquisador enquanto prática reflexiva. Para Elliott (1989, p. 250), o processo de reflexão que se dá pela pesquisa

[...] consiste em generalizações que são destilações retrospectivas a partir da experiência. Estas não são leis causais a partir das quais os professores podem predizer o resultado de um determinado curso de ação. Constituem, mais precisamente, relações entre fatores que, quando ponderados, parecem se repetir nas situações práticas com um grau razoável de freqüência. Tais generalizações atraem a atenção do docente para traços provavelmente relevantes da situação atual, que têm de ser examinados antes de selecionar um curso de ação. Diferentemente das leis causais, não dizem ao professor o que ele deve fazer, e sim proporcionam uma orientação geral para o diagnóstico de situações particulares. Se, ao deliberar, o docente verifica que algumas das relações antecipadas não se cumprem, isto não invalida as generalizações empregadas, já que cumpriram uma função muito importante de diagnóstico: ajudaram o docente a discernir qual é ou não o caso na situação atual. Apenas quando uma generalização deixa de ser aplicada à maioria das situações encontradas é que sua utilidade e valor como parte da provisão de conhecimento profissional começa a ser questionável.

Desse modo, a prática reflexiva, a partir da pesquisa e investigação na própria prática, constitui um proces- 
so dialético de geração da prática a partir da teoria e da teoria a partir da prática.

As críticas postas à concepção do professor como investigador, desenvolvida por Stenhouse, possibilitaram um avanço na reflexão e nas pesquisas sobre essa proposta de formação profissional centrada num processo de pesquisa. Concordando com a crítica desses autores, entendemos que a superação de tais limites se dará a partir de teorias que permitam aos professores entenderem as restrições impostas pela prática institucional e histórico social ao ensino, de modo a identificar o potencial transformador das práticas. Na mesma direção, Libâneo (1998) destaca a importância da apropriação e produção de teorias como marco para a melhoria das práticas de ensino e dos resultados. Contreras (2002) chama a atenção para o fato de que a prática dos professores precisa ser analisada, considerando que a sociedade é plural, no sentido da pluralidade de saberes, mas também desigual, no sentido das desigualdades sociais, econômicas, culturais e políticas. Assim, concorda com Carr (1996), ao apontar o caráter transitório e contingente da prática dos professores e a necessidade da transformação das mesma numa perspectiva crítica.

3.FUNDAMENTOS METODOLÓGICOS PARAA FORMAÇÃO DO PROFESSOR PESQUISADOR-REFLEXIVO NO PROCESSO DE ES-

\section{TÁGIO}

Pensamos que a perspectiva que mais contempla um processo de formação pela pesquisa no estágio profissional seja a metodologia da pesquisa-ação, com enfoque direcionado à pesquisa colaborativa.

Essa perspectiva tem se configurado como fertilizadora para as pesquisas cujo objetivo é o de colaborar com os processos de construção identitária de professores. Entendemos que o exercício da docência não se reduz à aplicação de modelos previamente estabelecidos, mas que, ao contrário, é construído na prática dos sujeitos-professores historicamente situados. Assim, um processo formativo mobilizaria os saberes da teoria da educação necessários à compreensão da prática docente, capazes de desenvolver as competências e habilidades para que os professores investiguem a própria atividade docente e, a partir dela, constituam os seus saberes-fazeres docentes, num processo contínuo de construção de novos saberes.

Compreendemos, também, que uma identidade profissional se constrói a partir da significação social da profissão, da revisão constante dos significados sociais da profissão, da revisão das tradições, mas também da reafirmação de práticas consagradas culturalmente e que permanecem significativas. Práticas que resistem a inovações porque são prenhes de saberes válidos às necessidades da 
realidade, do confronto entre as teorias e as práticas, da análise sistemática das práticas à luz das teorias existentes, da construção de novas teorias. Constroem-se, também, pelo significado que cada professor, enquanto ator e autor, confere à atividade docente no seu cotidiano a partir de seus valores, de seu modo de se situar no mundo, de sua história de vida, de suas representações, de seus saberes, de suas angústias e anseios, do sentido que tem em sua vida o ser professor, assim como a partir de sua rede de relações com outros professores, nas escolas, nos sindicatos e em outros agrupamentos.

Por isso, é importante mobilizar os saberes da experiência, os saberes pedagógicos e os saberes científicos, enquanto constitutivos da docência, nos processos de construção da identidade de professores (PIMENTA, 2000).

Essa perspectiva apresenta um novo paradigma sobre formação de professores e suas implicações sobre a profissão docente. Tendo emergido em diferentes países nos últimos 25 anos, esse paradigma configura-se como uma política de valorização e desenvolvimento pessoal-profissional dos professores e das instituições escolares, uma vez que supõe condições de trabalho propiciadoras da formação contínua dos professores.

Ao denominar o desenvolvimento do estágio como atividade de pesquisa, assumimos a perspectiva da pesquisa como colaborativa e/ou pes- quisa-ação, entendendo que sua finalidade é criar uma cultura de análise das práticas, tendo em vista suas transformações pelos professores com a colaboração dos professores da universidade e dos estagiários. Por concordarmos com Zeichner (1998, p. 223), para quem "a pesquisa colaborativa é um importante caminho para superar a divisão entre acadêmicos e professores, mas não é qualquer pesquisa colaborativa que faz isso", importava-nos configurá-la como pesquisa-ação. E, mais recentemente, como "pesquisa-ação crítica" (KINCHELOE, 1998, p. 180).

Um dos principais desafios da pesquisa colaborativa será o estabelecimento dos vínculos entre os pesquisadores da universidade, os estagiários e os professores da escola. Uma maneira de superar esse obstáculo inicial é partir das necessidades dos estagiários, dos professores e das escolas onde a prática se efetivará. Para isso, é preciso partir das inquietações fortemente vinculadas às práticas cotidianas, que emergem das necessidades que se apresentam no contexto escolar, e evitar 'começar' a pesquisa e o trabalho como se a universidade já tivesse a resposta para os problemas que a escola enfrenta. Também é necessário superar a representação de que os professores da universidade levam as respostas/receitas do que os professores da escola deveriam fazer para resolver seus problemas.

É importante que se diga que sem 
a conquista da relação de parceria e a confiança dos professores e alunos não é possível desenvolver esse trabalho de estágio como pesquisa. Por isso, é fundamental priorizar o diálogo sistemático das questões cotidianas com a colaboração dos professores que estão na escola e de outros instrumentos. Nesse sentido, ao longo do processo de estágio e da presença dessa atividade pode ser significativa a seleção de textos para estudos coletivos na escola, para propor questões, escrever, dialogar com os autores, envolver os alunos (futuros professores) e sistematizar as questões em alguns eixos centrais no processo de reelaboração do conhecimento que se dá pela pesquisa no estágio.

Nesse sentido, o trabalho de Garrido, Pimenta e Moura (2000) é central na evidência de uma experiência que pode ser significativa no processo de formação inicial de professores, especialmente quando eles compreendem que o saber sobre o ensino não se dá antes do fazer, como estabelece o paradigma da racionalidade técni$\mathrm{ca}$, mas se inicia pelo questionamento da prática. Respaldado em conhecimentos teóricos, esse saber é produto do entendimento dos problemas vivenciados e da criação de novas soluções, visando a sua superação. Daí a necessidade da introdução do futuro professor, desde o início da sua formação, no universo da prática. Ele aprenderia a ser professor refletindo sobre sua prática, problematizando- a, distinguindo as dificuldades que ela coloca, pensando alternativas de solução, testando-as, procurando esclarecer razões subjacentes a suas ações, observando as reações dos alunos, verificando como aprendem, procurando entender o significado das questões e das respostas que eles formulam. Essas atividades seriam próprias de uma atitude investigativa, caracterizando o professor como produtor de conhecimentos práticos sobre o ensino. Tal perspectiva deve reorientar os cursos de formação, especialmente no que diz respeito às relações dialógicas entre teoria e prática e à importância da aprendizagem de procedimentos investigativos e de interpretação qualitativa dos dados. Nesse processo, fica explicita a importância da atuação coletiva dos professores no espaço escolar, propiciador de trocas reflexivas sobre as práticas, o que qualifica a profissão do professor, definindo-o como intelectual em processo contínuo de formação.

Nesse sentido, a pesquisa da prática na formação e identidade profissional de professores tem sido desenvolvida por diferentes autores. $\mathrm{Na}$ perspectiva do desenvolvimento de pequenos projetos teoricamente sustentados podemos lembrar os trabalhos de Sacristán (1983; 1992; 1999), e de Porlán (1987). Sobre equipe escolar, reflexão na ação e pesquisa da prática, podemos destacar as pesquisas de Contreras (1997), Goodson (1993), Zeichner (1991; 1998), Fiorentini 
(1998), Elliot (1993), Heargreaves (1997), Baird (1986), Pimenta (1998), Penteado (1998), entre outros trabalhos significativos que procuram respaldar a produção do conhecimento na direção da pesquisa que se dá no espaço da escola, como açãocolaborativa em vista de mudanças no universo do ensino.

Tendo em vista melhor explicitar o Estágio Profissional neste horizonte de trabalho, assumimos como objetivos: articular o desenvolvimento profissional dos professores envolvidos; analisar os processos de construção dos saberes pedagógicos pela equipe escolar; estimular mudanças na cultura organizacional escolar; oferecer subsídios para as políticas públicas de formação contínua de professores.

Nosso pressuposto em relação à pesquisa foi o de que todo professor pode produzir conhecimentos (práticos/teóricos) sobre o ensino, na medida em que propõe inovações nas práticas, transformando-as e re-orientando-as, visando à superação de dificuldades e necessidades detectadas pela investigação reflexivacolaborativa.

Os resultados esperados dessa colaboração podem ser resumidos em mudanças pedagógicas que produziram valorização do trabalho, crescimento pessoal, compromisso profissional, desenvolvimento de uma cultura de análise e de práticas organizacionais participativas.

\section{QUESTÕES QUE ORIENTAMA PRÁTICA DO ESTÁGIO COMO PROCESSO DE PESQUISA}

O esboço que até aqui realizamos da problemática epistemológica da pesquisa da prática na perspectiva da pesquisa ação-colaborativa, emerge do processo de pesquisas anteriores e tem sido colocado por outros pesquisadores de nosso país e de outros, o que evidencia a importância de seu aprofundamento.

Segundo Pimenta e Lima (2004, p. 46), "a pesquisa no estágio é uma estratégia, um método, uma possibilidade de formação do estagiário como futuro professor. Ela pode ser também uma possibilidade de formação e desenvolvimento dos professores da escola na relação com os estagiários". Logo, essa pesquisa se traduz na mobilização de saberes que permitem a ampliação e análise dos contextos onde os estágios se realizam como pesquisa. Tal perspectiva de estágio implica posturas diferenciadas diante do conhecimento. Supõe que se busque novo conhecimento na relação entre as explicações existentes e os dados novos que a realidade impõe, os quais são percebidos na postura investigativa.

É importante que se diga que, no Brasil, o movimento de valorização da pesquisa no estágio tem suas origens no início dos anos 1990, a partir do questionamento que então se fazia sobre a indissociabilidade entre teoria e prática. Assim, a formulação do 
“estágio como atividade teórica instrumentalizadora da práxis" (PIMENTA, 1994, p. 121), tendo por base a concepção do "professor como intelectual"'(GIROUX, 1997) em processo de formação e a educação como um processo dialético de desenvolvimento do ser humano historicamente situado, abriu espaço para um início de compreensão do estágio como uma investigação das práticas pedagógicas nas instituições de educativas (PIMENTA e LIMA, 2004).

Segundo Lima (2001b), essa visão mais abrangente e contextualizada do estágio indica, para além da instrumentalização técnica da função docente, um profissional pensante, que vive num determinado espaço e num certo tempo histórico, capaz de vislumbrar o caráter coletivo e social de sua profissão.

Do ponto de vista operacional, o estágio como processo de construção do conhecimento orientado pela prática da pesquisa, centrado no conceito de professor-pesquisador e professor-reflexivo, pode ser melhor explicitado no se segue.

Independentemente do "locus" e da modalidade, entende-se que a formação do professor não se esgota na formação inicial. Ele deve estar preparado para exercer uma prática pedagógica cotidiana de formação continuada, mediada pela teoria e pela constante reflexão contextualizada e coletiva. Assim, a formação deve estar voltada para uma atividade reflexiva e investigativa, para a superação de uma matriz formativa tradicional baseada meramente na formação profissional, buscando o domínio do saber pedagógico. Para que a ação pedagógica do professor esteja pautada em uma atitude reflexiva, crítica e investigativa, é fundamental que ele possa vivenciar essa mesma realidade durante os cursos que formam para o magistério (FERRAZ, 2000). A formação do professor começa pela incorporação do perfil profissional definido, considerando-se, especialmente, a inserção local e regional. Assim, o professor deve ser preparado para:

- Propor seu modo próprio e criativo de teorizar e praticar a docência referenciada na pesqui$s a$, renovando-a constantemente e mantendo-a como fonte principal de sua capacidade inventiva, por meio de um processo reflexivo sobre sua prática e o contexto social onde está inserido.

- Estimular a aprendizagem que se desenvolve a partir de uma atitude investigativa, considerando o estágio social e intelectual de desenvolvimento do aluno e tendo como objetivo maior fazer dele um parceiro de trabalho, ativo, participativo, produtivo, reconstrutivo (DEMO, 1997).

-Ser um acolhedor da diversidade, aberto às inovações pedagógicas e tecnológicas, comprometido com o social, com o sucesso e as dificuldades de seus educandos.

A estrutura e a ação dessa pro- 
posta quer possibilitar e permitir a formação do docente crítico, reflexivo, que incorpore a pesquisa como princípio educativo, numa perspectiva sócio-histórica. Do mesmo modo que quer tudo isso, impõe superar o processo de ensino fragmentado, privilegiando ações integradas e pensando o currículo em sua amplitude de saberes e diversidade de modalidades de execução. Concebido desse modo, o currículo expressa as bases processuais de formação, contemplando os diversos processos relacionados com a formação profissional, cultural e humanística dos estudantes.

Convém ressaltar que o currículo se constrói a partir da definição coletiva do projeto pedagógico do curso, em um processo no qual os critérios de seleção e organização dos referenciais de conhecimentos, metodologias, atitudes e valores sejam estabelecidos por todos os atores do processo.

Com esse entendimento, o curso há de propor, no seu currículo, um trajeto de formação que privilegie a:

-ndissociabilidade entre ensino, pesquisa e extensão;

- interdisciplinaridade

transdisciplinaridade;

-formação profissional para a cidadania;

-autonomia intelectual;

-responsabilidade, compromisso

e solidariedade social.

Entendemos que a articulação teoria-prática deve fazer parte do direcionamento dado em todo o pro- cesso de formação docente. As experiências de pesquisa vivenciadas no decorrer da formação possibilitam ao estudante perceber que a prática atualiza e interroga a teoria. Desse modo, assim como Esteban e Zaccur (apud Ferraz, 2000, p. 63), reconhecemos que "a prática sinaliza questões e a teoria ajuda a apreender estas sinalizações, a interpretá-las e a propor alternativas. [...] A prática é o local de questionamento, do mesmo modo que é objeto deste questionamento, sempre mediado pela teoria".

Nesse entendimento, a sala de aula - tomada como espaço de investigação - apresenta ao professor a possibilidade de conhecer, refletir e entender os processos individuais e dinâmicos de aprendizagem de seus alunos, suscitando constantemente novos questionamentos, favorecendo a revisão de conclusões iniciais, à luz de novas observações e também do conhecimento já consagrado na literatura. A prática é o objeto de investigação permanente do professor, durante sua formação e na ação profissional. Esse olhar permite que se dê a construção de métodos de ensino que garantam o aprendizado dos conhecimentos e a maneira de produzi-los. É fundamental, ainda, considerar que o desenvolvimento pedagógico a partir das práticas permite dar conta da complexidade do processo de formação humana, por sua sintonia permanente com o movimento da realidade (Caldart, 2001).

De modo geral, a proposta articu- 
la todos os elementos fundamentais no processo formativo, expresso no gráfico a seguir:

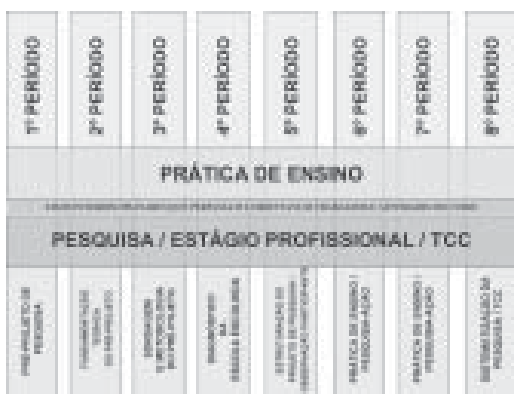

\section{REFERÊNCIAS}

ABDALLA, M. F. B. Formação e desenvolvimento profissional do professor: o aprender da profissão (um estudo em escola pública). Tese (Doutorado) FEUSP, 2000.

ANDRÉ, M. O papel da pesquisa na prática e na formação dos professores. Campinas: Papirus, 2002.

ALVES, N. (Org.). Criar currículo no cotidiano. São Paulo: Cortez, 2002.

ALARCÃO, I. Porque da admiração dos professores por Donald Schön? Revista da Faculdade de Educação da USP, v. 22, n. 2, 1996.

ALMEIDA, M. I. O sindicato como instância formadora dos professores: novas contribuições ao desenvolvimento profissional. Tese (Doutorado) - FEUSP, 1999.

BAIRD, J. R.; MITCHELL, I .J.; NORTHFIELD, J. R. Teachers as researchers: the rationale; the reality. Research in Science Education, n. 17, p. 129-138, 1987.
BREZINSKI, Í. Pedagogia, pedagogos e formação de professores. Campinas: Papirus, 1996.

CARR, W. Una teoría para la educación: hacia una investigación educativa crítica. Madrid: Morata, 1996.

CARR, W.; KEMMIS, S. Becoming critical: education, knowledg and action research. Londres: Falmer Press, 1986.

CARR, W.; KEMMIS, S. Una teoria para la educación: hacia una investigacion educativa critica. Madrid: Morata, 1996.

CHARLOT, B.; BEILLEROT, J. (Orgs.). La construction des politiques d'éducation et de formation. Paris: PUF, 1995.

CONTRERAS, J. La autonomia del profesorado. Madrid: Morata, 1997.

Autonomia de professores. São Paulo: Cortez, 2002.

DEMO, P. Pesquisa: princípio científico e educativo. 9. ed. São Paulo: Cortez, 2002.

ELLIOT, J. Reconstructing teacher education. London: The Falmer Press, 1993.

Recolocando a pesquisa-ação em seu lugar original e próprio. In: FIORENTINI; GERALDI; PEREIRA. (Orgs.). Cartografias do trabalho docente. Campinas: Mercado de Letras, 1998.

Teacher evaluation and teaching as a moral science. In: HOLLY, M.; MALOUCHLIN C. S. (Orgs.). Perspectives on teacher professional development. London: The Falmer Press, 1989. p. 239-258.

La investigación-acción en educación. Madri: Morata, 1990.

FRANCO, L. F. Racionalidade técnica,

Olhar de professor, Ponta Grossa, 7(2): 57-76, 2004. $\overline{73}$ 
pesquisa colaborativa e desenvolvimento profissional de professores. In: PIMENTA; GHEDIN (Orgs.). Professor reflexivo no Brasil: gênese e crítica de um conceito. São Paulo: Cortez, 2002.

FRANCO, M. A. A pesquisa fecundando a prática docente: fundamentos epistemológicos. (Mestrado) - FEUSP, 2000.

FRANCO, M. A. A pedagogia como ciência da educação: entre práxis e epistemologia. Tese (Doutorado) - USP, São Paulo, 2002.

GARRIDO, E. et al. A pesquisa colaborativa na escola como abordagem facilitadora para o desenvolvimento da profissão do professor. In: MARIN, A. J. (Org.). Educação continuada. Campinas: Papirus, 2000. p. 89-112.

GATTI, B. Formação de professores e carreira. Campinas: Autores Associados, 1997.

GAUTHIER, C. et al. Por uma teoria da pedagogia: pesquisas contemporâneas sobre o saber docente. Ijuí: Unijui, 1998.

GHEDIN, E. Professor teflexivo: da alienação da técnica à autonomia da crítica. In: PIMENTA; GHEDIN. (Orgs.). Professor reflexivo no Brasil: gênese e crítica de um conceito. São Paulo: Cortez, 2002.

GIROUX, H. Os professores como intelectuais. Porto Alegre: Artes Médicas, 1997.

GUIMARÃES, V. Saberes docentes e identidade profissional: um estudo a partir da Licenciatura. Tese (Doutorado) - FEUSP. 2001.

HABERMAS, J. Conhecimento e interesse. Rio de Janeiro: Zahar, 1982.
HARGREAVES, A. Profesorado, cultura y postmodernidad. Madrid: Morata, 1996.

HOUSSAYE, J. Une illusion pédagogique? Cahiers Pédagogiques, Paris, n. 334, p. 28-31, 1995.

KINCHELOE, J. A formação do professor como compromisso político: mapeando o pós-moderno. Porto Alegre: Artes Médicas, 1998.

LAWN, M. Atrapados por el trabajo diario: las posibilidades de investigar de los professores. In: CARR, W. (Org.). Calidad de la enseñanza e investigación-acción. Sevilha: Díada, 1993.

LIBÂNEO, J. C. Adeus professor, adeus professora? São Paulo: Cortez, 1998.

LIMA, M. S. L. A formação contínua dos professores nos caminhos e descaminhos do desenvolvimento profissional. Tese (Doutorado) - FEUSP, São Paulo, 2001a.

A hora da prática: reflexões sobre o estágio supervisionado e a ação docente. Fortaleza: UECE, 2001 b.

LÜDKE, M. Combinando pesquisa e prática no trabalho e na formação de professores. Revista Ande, a. 12, n. 19, p. 3138, 1993

MACHADO, N. J. Epistemologia e didática: as concepções de conhecimento e inteligência e a prática docente. São Paulo: Cortez, 1995.

MARIN, A. J. Investigando com os professores na escola pública. In: IX ENDIPE, Anais, v. 1, n. 1, 1998.

MIZUKAMI, M. G. N.; RODRIGUES, A. M. Formação de professores: práticas pedagógicas e escola. São Carlos: 
Edufscar, 2002.

MORIN, E. Ciência com consciência. Barcelona: Anthropos, 1994.

PÉREZ GOMEZ, A. Autonomía profesional del docente y control democrático de la practica educativa. Volver a pensar la educación: prácticas y discursos educativos. 2. ed. In: CONGRESO INTERNACIONAL DE DIDÁCTICA. Madrid: Morata, 1995.

PERRENOUD, P. Práticas pedagógicas, profissão docente e formação. Lisboa: Dom Quixote, 1992.

PIMENTA, S. G. O estágio na formação de professores: unidade teoria e prática? São Paulo: Cortez, 1994.

Formação de professores: saberes da docência e identidade do professor. Revista da Faculdade de Educação da USP, v. 22, n. 2, p. 72-89, 1996.

. A Didática como mediação na construção da identidade do professor: uma experiência de ensino e pesquisa. In: ANDRÉ, M.; OLIVEIRA, M. R. (Orgs.). Alternativas do ensino de didática. Campinas: Papirus. 1997. p. 37-70.

A prática (e a teoria) docente resignificando a Didática. In: OLIVEIRA (Org.). Confluências e divergências entre didática e currículo. Campinas: Papirus, 1998. p. 153-176.

(Org.). Saberes pedagógicos e atividade docente. São Paulo: Cortez, 1999.

PIMENTA, Selma G. Saberes pedagógicos e atividade docente. São Paulo: Cortez, 2000.

. Itinerário teórico/metodológico de uma pesquisadora. In: PIMENTA, S. G. Professores, pesquisa e didática. Cam- pinas: Papirus, 2002.

Professor reflexivo: construindo uma crítica. In: PIMENTA; GHEDIN. (Orgs.). Professor reflexivo no Brasil: gênese e crítica de um conceito. São Paulo: Cortez, 2002. p. 12-52.

PIMENTA, S. G.; GHEDIN, E. (Orgs.). Professor reflexivo no Brasil: gênese e crítica de um conceito. São Paulo: Cortez, 2002. $224 \mathrm{p}$

PIMENTA, S. G.; LIBÂNEO, J. C. Formação dos profissionais da educação: visão crítica e perspectivas de mudança. In: PIMENTA, S. G. (Org). Pedagogia e pedagogos: caminhos e perspectivas. São Paulo: Cortez, Ed. 2002c. p. 11-58.

PIMENTA, S. G.; LIMA, M. S. L. Estágio e docência. São Paulo: Cortez, 2004.

PORLÁN, R. El maestro como investigador en el aula: investigar para conocer, conocer para enseñar. Investigación en la Escuela, n. 1, p. 63-70, 1987.

SACRISTÁN, J. G. Poderes instáveis em educação. Porto alegre: Artes Médicas, 1999.

Tendências investigativas na formação de professores. Tradução de José C. Libâneo. In: PIMENTA; GHEDIN. (Orgs.). Professor reflexivo no Brasil: gênese e crítica do conceito. São Paulo: Cortez, 2002.

STENHOUSE, L. La investigación como base de la enseñanza. Madrid: Morata, 1987.

THIOLLENT, M. Metodologia da pesquisa-ação. São Paulo: Cortez, 1998.

ZARAGOZA, J. M. E. O mal estar docente: a sala de aula e a saúde dos professores. Bauru, SP: Edusc, 1999.

ZEICHNER, K. El maestro como 
profesional reflexivo. Cuadernos de pedagogía, n. 220, p. 44-49, 1993.

Para além da divisão entre professor-pesquisador e pesquisador-acadêmico. In: FIORENTINI; GERALDI; PEREIRA. (Orgs.). Cartografias do trabalho docente. Campinas: Mercado de Letras, 1998.

ZEICHNER, K.; LISTON, D. P. Formación del profesorado y condiciones sociales de la escolarización. Madrid: Morata, 1990. 